\title{
ANÁLISE DA VULNERABILIDADE TECNOLÓGICA DAS FAMÍLIAS DA ZONA RURAL DO MUNICÍPIO DE GADO BRAVO-PB
}

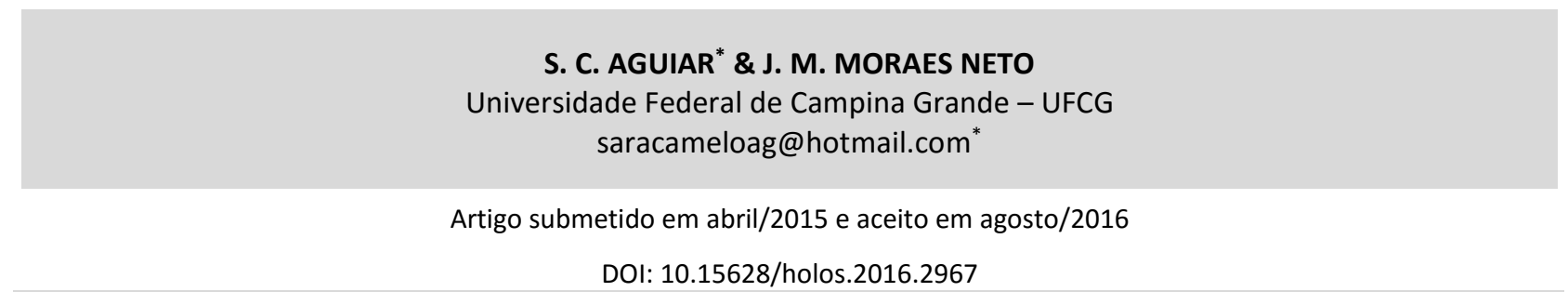

\section{RESUMO}

O presente trabalho teve como área de estudo a zona rural do município de Gado Bravo, localizado na mesorregião do Agreste Paraibano e seu objetivo é calcular e analisar a vulnerabilidade tecnológica das famílias da zona rural do município. Foi empregada uma abordagem quanti-qualitativa com uma pesquisa do tipo exploratória e foram aplicados 83 questionários às famílias. Conforme os resultados, a vulnerabilidade tecnológica das famílias da zona rural de Gado Bravo alcançou o índice de $68,65 \%$, que consiste em uma vulnerabilidade muito alta $(>45 \%)$ e é resultante de elementos como a pouca duração da água armazenada e a ausência de planejamento da produção, que por sua vez são decorrentes da ínfima presença de assistência técnica devido ao descaso do poder público.

PALAVRAS-CHAVE: Vulnerabilidade tecnológica, Famílias, Gado Bravo.

\section{ANALYSIS OF VULNERABILITY TECHNOLOGY OF FAMILIES OF RURAL AREA OF THE MUNICIPALITY OF GADO BRAVO-PB}

\section{ABSTRACT}

The present work was to study area the rural municipality of Gado Bravo, located in the middle region of the Paraíba arid and your goal is to calculate and analyze the technological vulnerability of families in rural areas of the municipality. Was used a quantitative-qualitative approach to a survey of exploratory and applied 83 questionnaires to households. According to the results, technological vulnerability of rural families Gado Bravo reached $68.65 \%$ index, consisting of a very high vulnerability (> 45\%) and is the result of factors such as the short duration of the stored water and the lack of production planning, which in turn are due to the presence of tiny technical assistance due to the indifference of the government.

KEYWORDS: Technological vulnerability, Families, Gado Bravo. 


\section{INTRODUÇÃO}

A definição do termo tecnologia remonta uma confusão histórica, um conflito inclusive para distinguir tecnologia e ciência, mas é consenso que se trata de um termo em constante e acelerada transformação.

De maneira geral, a tecnologia abrange não apenas os produtos artificiais fabricados pela humanidade, bem como os processos de produção, englobando máquinas e recursos necessários em um sistema produtivo. Afora isso, abrange também as metodologias, as competências, as capacidades e os conhecimentos necessários às atividades produtivas, e também o próprio uso dos produtos introduzidos na conjuntura sócio-cultural (ACEVEDO DÍAZ, 1996).

O presente estudo enfoca a vulnerabilidade da faceta mais utilitarista do termo tecnologia, isto é, a tecnologia como sinônimo de técnica, um conjunto de conhecimentos expresso nas habilidades e competências que facilitam a vida humana ao longo da história. (VERASZTO, et al, 2008).

Desse modo, esse artigo aborda as condições de produção, o acesso e a utilização dos recursos tecnológicos das famílias da zona rural de Gado Bravo, com o objetivo de calcular e analisar a vulnerabilidade tecnológica dessas famílias.

A relevância da pesquisa consiste no estudo e divulgação das enormes e frequentes dificuldades enfrentadas por municípios pequenos, como Gado Bravo, muitas vezes marginalizados pela ciência e pela mídia. Por isso, é importante que a realidade desses municípios sejam denunciadas e introduzidas no domínio científico, para que a realidade vivenciada em seus territórios se torne objeto de investigação passível de melhorias para seus munícipes.

\section{REVISÃO BIBLIOGRÁFICA}

O conceito de vulnerabilidade é multidimensional e possui diversos sentidos, seu significado se modifica conforme as diferentes abordagens, linhas de estudo e áreas do conhecimento.

Apesar da diversidade e consequente imprecisão conceitual de vulnerabilidade, considerando a afinidade com o objeto investigado, o presente estudo adotou o seguinte conceito: vulnerabilidade consiste na predisposição ou na susceptibilidade física, econômica, política ou social que tem uma comunidade de ser afetada ou de sofrer danos, que pode resultar na degradação ambiental ou social, em caso da manifestação de um fenômeno desestabilizador de origem natural ou antrópica (CARDONA, 2001).

Para expandir um pouco mais a noção de vulnerabilidade, ela também significa conceber antecipadamente a existência da probabilidade de exposição a algo negativo e calcular qual a capacidade de responder ao agravo sofrido, uma vez que "estar vulnerável" decorre da exposição a uma situação de risco ou a um evento de perigo (HOGAN; MARANDOLA JR., 2005). Desse modo, o aumento da vulnerabilidade resulta na diminuição da capacidade de resposta e vice-versa.

Essa diversidade conceitual certamente advém das variadas formas de origem que a vulnerabilidade pode ter, pois ela se dá conforme as condições sociais, econômicas e culturais de 
determinada população, e tais condições são bastante diversificadas e têm forte influência de políticas públicas de desenvolvimento.

Desse modo, a vulnerabilidade é intrínseca a uma dada população e se diferencia conforme suas possibilidades sociais, econômicas e culturais. Ou seja, consequentemente a população que possui menos recursos possui mais dificuldade de adaptação ou resposta e é mais vulnerável, visto que a capacidade de adaptação advém da "riqueza, tecnologia, educação, informação, habilidades, infraestrutura, acesso a recursos e capacidade de gestão" (IPCC, 2001, p. 6).

Nesse sentido, vulnerabilidade é uma temática desenvolvida para denominar populações inseguras que não possuem condições suficientes para se adaptarem ou responderem a desastres, que são eventos que acontecem, muitas vezes, de forma repentina e inesperada, causando interações intensas, demostradas por perdas de vida e saúde da população, uma destruição ou perda de bens, de uma coletividade de danos severos sobre o meio ambiente (CARDONA, 2001).

Conforme Wilches-Chaux (1989) existem diferentes formas de vulnerabilidade que podem afetar uma sociedade, dentre elas a vulnerabilidade tecnológica que diz respeito à fragilidade no acesso e utilização de técnicas, ferramentas e máquinas.

A vulnerabilidade tecnológica é comumente vivenciada nos espaços rurais, sobretudo nas pequenas propriedades cujas atividades produtivas são realizadas pelas próprias famílias, pois ainda prevalece a utilização de técnicas rudimentares ensinadas de geração para geração e os órgãos públicos responsáveis pelo apoio a pequenos produtores rurais são ineficientes quando não ausentes. Desse modo, as famílias da zona rural são fadadas a produzirem em suas propriedades à custa de muito esforço físico e com baixa eficiência, resultando na fragilização até dos meios de sobrevivência dessas famílias.

\section{METODOLOGIA}

O município de Gado Bravo se localiza na mesorregião do Agreste Paraibano, mais precisamente na microrregião de Umbuzeiro, entre as coordenadas geográficas $07^{\circ} 34^{\prime} 58^{\prime \prime}$ de latitude Sul e $35^{\circ} 47^{\prime} 27^{\prime \prime}$ de longitude Oeste e possui uma área territorial de 192,406 km² $^{2}$ (CIDADE BARSIL, 2012).

Gado Bravo possui clima semiárido e sua pluviometria anual média, em 2013, foi de 500 a750mm (PARAÍBA, 2014).

Em 2010, Gado Bravo possuía uma população de 8. 376 habitantes, sendo 908 residentes da zona urbana e 7.468 residentes da zona rural (IBGE, 2014). A predominância da população da zona rural se deve à ausência de postos de trabalho na zona urbana do município e a presença marcante da pecuária leiteira na zona rural que consiste na principal atividade econômica do município e fonte de redimento de suas famílias.

A realização do estudo teve uma abordagem quanti-qualitativa e adotou uma pesquisa do tipo exploratória.

Para analisar o índice de vulnerabilidade tecnológica das famílias da zona rural de Gado Bravo o presente estudo se valeu da metodologia de Rocha (1997), desenvolvida para o estado do Rio Grande do Sul e adaptada por Araújo (2002), Silva (2002), Moraes Neto (2003), Sousa (2007) e 
Duarte (2008) para o Semiárido paraibano. De acordo com a metodologia, foi realizado um levantamento por meio da aplicação de questionários, que considerou o fator tecnológico e suas respectivas variáveis. Após a aplicação dos questionários os dados obtidos foram tabulados considerando valores de referência, que são destinados a cada variável dos questionários.

Foram aplicados 83 questionários entre os meses de julho e setembro de 2014. Em seguida, para obtenção do índice de vulnerabilidade tecnológica os dados foram tabulados em planilhas e calculados a partir da Equação (1): $y=a x+b$. Onde, y é o índice da vulnerabilidade que varia de 0 (nulo) a 100 (máximo); a e b são constantes para cada fator; e x é o valor significativo encontrado.

E por fim, para classificação do índice de vulnerabilidade tecnológica do município, foi utilizada a classificação indicada por Barbosa (1997), que possui quatro classes, cujos valores, conforme a Tabela, variam de 0\% (vulnerabilidade nula) a 100\% (vulnerabilidade máxima).

Tabela 1: Classes de vulnerabilidade.

\begin{tabular}{c|c|c|c}
\hline Baixa & Moderada & Alta & Muito Alta \\
\hline $0 \%$ a $15 \%$ & $16 \%$ a $30 \%$ & $31 \%$ a $45 \%$ & $>45 \%$ \\
\hline
\end{tabular}

\section{RESULTADOS E DISCUSSÕES}

Segundo os dados obtidos, a vulnerabilidade tecnológica das famílias da zona rural de Gado Bravo como mostra a Figura 1 alcançou o índice de 68,65\%, que é considerada, segundo Barbosa (1997), uma vulnerabilidade muito alta (>45\%).

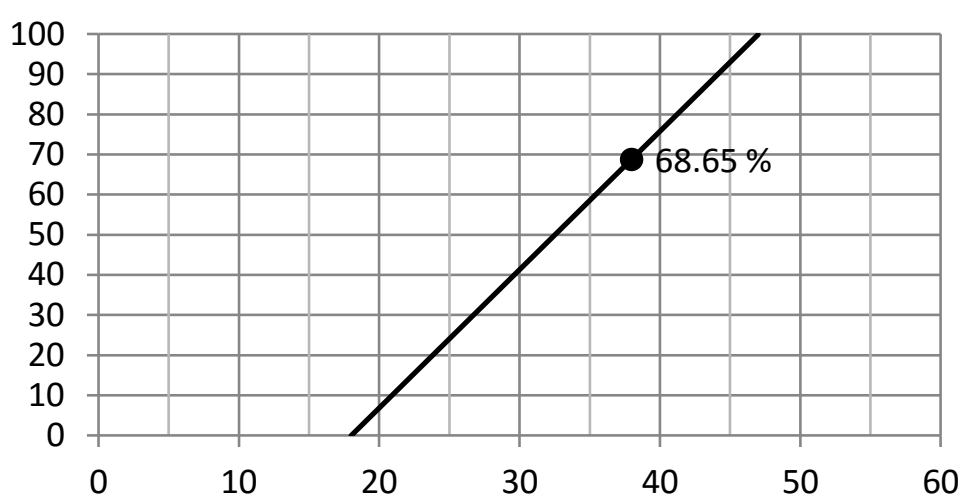

Figura 1: Índice de vulnerabilidade tecnológica das famílias da zona rural de Gado Bravo.

A vulnerabilidade tecnológica da zona rural de Gado Bravo supera o índice registrado no município de Cabaceiras-PB, que segundo Patrício (2013) é de $57,84 \%$ e já é considerada uma vulnerabilidade muito alta.

$\mathrm{Na}$ primeira variável da vulnerabilidade tecnológica é abordado o tipo de posse da propriedade, conforme a Figura 2, 75,9\% das famílias responderam que são proprietárias, 9,6\% são meeiras, novamente $9,6 \%$ são ocupantes e $2,4 \%$ se disseram que são arrendatárias. 


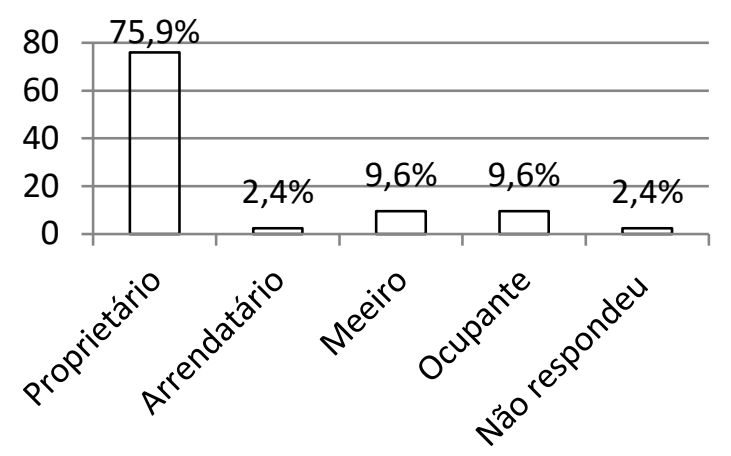

Figura 2: Tipo de posse da propriedade.

A grande maioria das famílias da zona rural de Gado Bravo (75,9\%) é proprietárias da área em que residem e produzem, porém o município ainda conta com práticas antigas de cessão de terras como o arrendamento $(9,6 \%)$ e o sistema de "meia" (9,6\%), ambas possuem uma clara dependência material e financeira das famílias em relação aos proprietários da terra, sobretudo as meeiras. Além disso, as famílias ditas ocupantes estão em situação ainda mais preocupante $(9,6 \%)$, pois a ocupação de terra alheia é ilegal e é consequentemente uma potencial área de conflitos.

No tocante ao uso do solo, segundo a Figura 3, 75,9\% das famílias questionadas responderam que seguem o declive, $12 \%$ usam em nível e outras $12 \%$ não responderam.

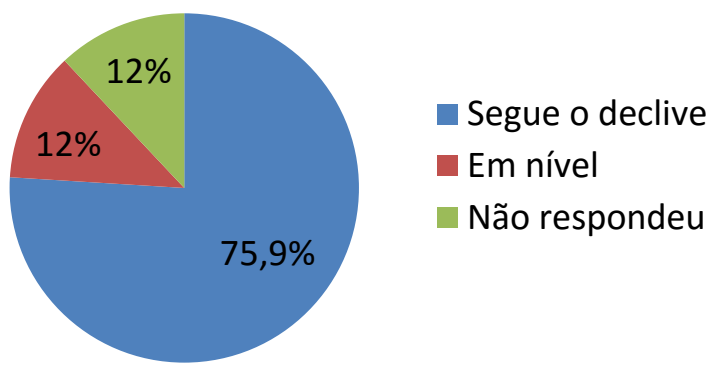

Figura 3: Uso do solo.

A expressiva maioria $(75,9 \%)$ das famílias da zona rural de Gado Bravo contribui para a erosão do solo de suas propriedades e assoreamento de rios e açudes, uma vez que plantam seguindo o declive do terreno como mostra a Fotografia 1, o mesmo não aconteceria se assim como a minoria (12\%) plantassem em curvas de nível, além de evitar a erosão também manteriam os nutrientes e a umidade por mais tempo no solo.

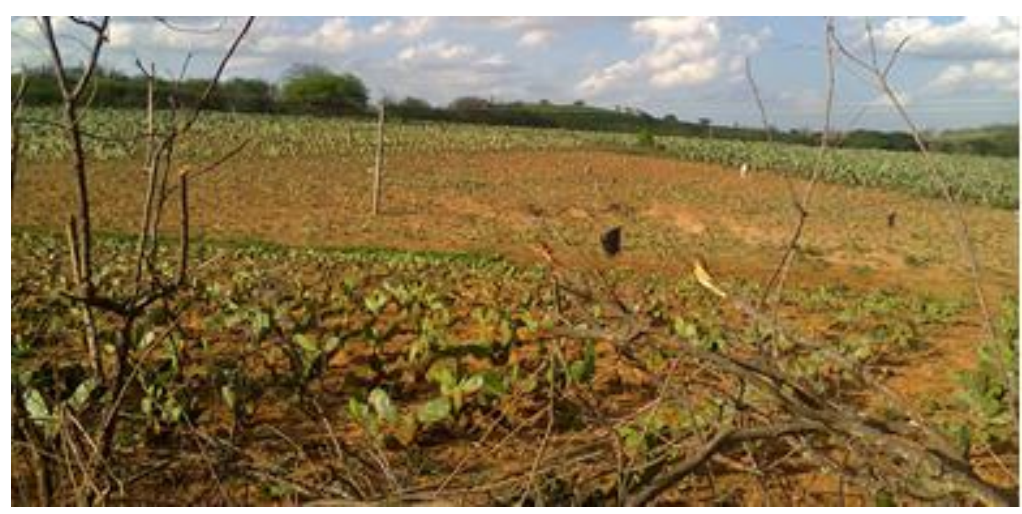

Fotografia 1: Plantio de palma forrageira em declive. 
O plantio em declive ainda é uma prática muito comum na zona rural, o estudo de Farias et al. (2013), sobre a vulnerabilidade tecnológica da população do entorno da bacia hidráulica do açude Manoel Marcionílio, Taperoá-PB, mostra que $86,7 \%$ dessa população plantam suas lavouras em declive, ou seja, é uma prática que está ainda muito arraigada aos costumes da população rural e que demanda sobretudo informação sobre os malefícios essa prática pode causar.

Quanto ao uso de práticas de conservação, conforme a Figura 5, 96,3\% das famílias disseram não usar e apenas 3,6\% afirmaram o uso.

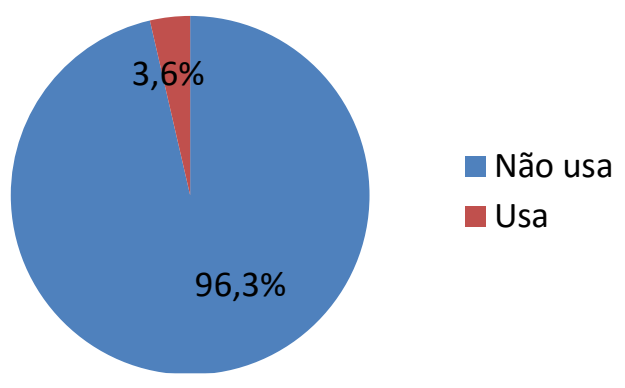

Figura 4: Práticas de conservação.

Esses dados significam que quase a totalidade das famílias da zona rural de Gado Bravo $(96,3 \%)$ não realizam práticas que mitigam efeitos como a erosão exemplificada na Fotografia 2 , portanto, não conciliam exploração econômica e conservação dos recursos naturais de suas propriedades, imputando um limite a vida útil de sua terra que cessará o rendimento proveniente da mesma. A realização de práticas como plantio de leguminosas em consórcio com gramíneas, rotação de pasto e de culturas, cultivo em nível, conservação de matas ciliares, dentre outras apontariam para outra realidade que é vivenciada por apenas uma minoria das famílias questionadas (3,6\%).

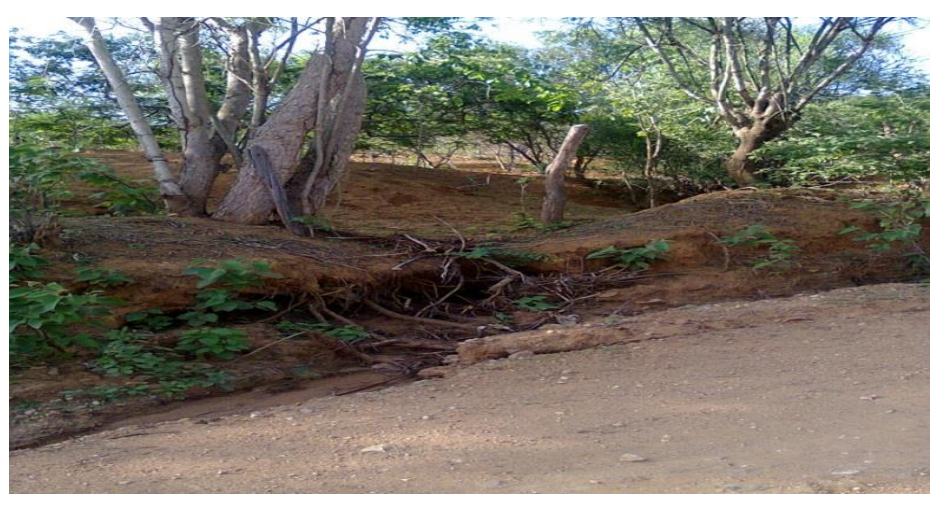

Fotografia 2: Erosão.

É um percentual muito expressivo de famílias que não contribuem para a conservação das terras de suas propriedades, expressivamente maior inclusive ao número registrado na zona rural do município de Cabaceiras-PB que foi de $66,7 \%$ (PATRícIO, 2013). Ou seja, as famílias da zona rural de Gado Bravo se encontram muito aquém nesse requisito que é fundamental para manterem suas terras produtivas e conservarem os corpos hídricos da região e que são elementos primordiais para as mesmas.

Na Figura 5, se tratando do uso de irrigação, $89,1 \%$ das famílias disseram não usar, $8,4 \%$ usam ocasionalmente e apenas 1,2\% fazem uso regular. 


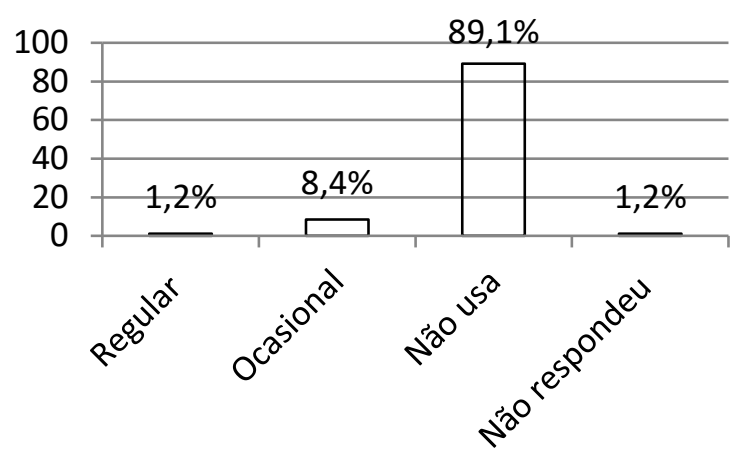

Figura 5: Irrigação.

Isto é, novamente quase o total das famílias da zona rural de Gado Bravo $(89,1 \%)$ não conta com uma prática que as apoiaria no seu dia a dia, uma vez que não dispõem do fornecimento controlado de água para o plantio de culturas, só uma pequena parcela das famílias conta com a irrigação seja de forma ocasional $(8,4 \%)$ ou regular (1,2\%). Isso é resultante primeiramente da escassez de água no município, mas em determinados momentos é reflexo tão somente da ausência de orientação técnica a essas famílias, conforme será abordado no parágrafo subsequente.

Embora ainda não seja um dado desejável nesse quesito o município se encontra em uma situação menos desconfortável que a população do entorno da bacia hidráulica do açude Manoel Marcionílio, Taperoá-PB, onde 100\% dessa população não usa irrigação (FARIAS, et al, 2013). Ou seja, a irrigação ainda é uma técnica pouco presente no interior paraibano, sobretudo por falta de informação a seu respeito, pois mesmo de acordo com a disponibilidade hídrica da região a irrigação viabiliza um cultivo mais estendido durante o ano.

No tocante a assistência técnica, segundo Figura $6,83,1 \%$ das famílias responderam não receber esse serviço, $10,8 \%$ disseram ter ocasionalmente e somente $4,8 \%$ têm regularmente.

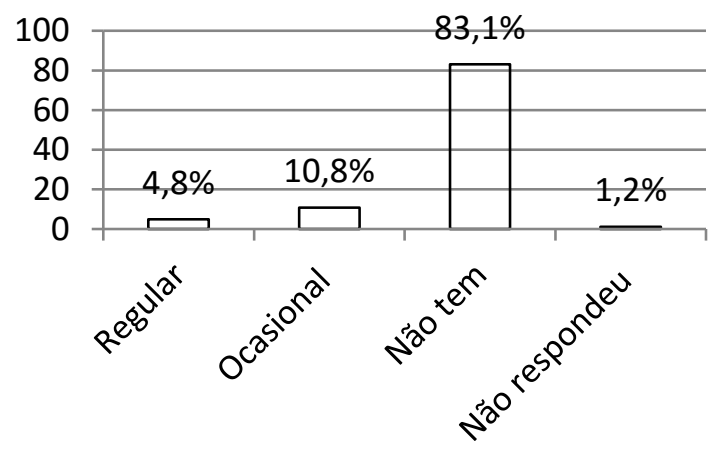

Figura 6: Assistência técnica.

Ou seja, além das dificuldades presentes no cotidiano das famílias da zona rural de Gado Bravo, como a escassez e irregularidade das chuvas e as poucas fontes de renda, a expressiva maioria delas $(83,1 \%)$ é abandonada pelo poder público, pois apesar do município contar com um posto da Empresa de Assistência Técnica e Extensão Rural - EMATER, as famílias não recebem nenhum tipo de assistência técnica por parte dela, que tem uma atuação meramente institucional 
e realiza precariamente apenas serviços burocráticos. Embora a Lei 3.824, de 12 de dezembro de 1975, que criou a EMATER - PB afirma que um de seus objetivos é:

II - Planejar, coordenar e executar programas de assistência técnica e extensão rural, visando a difusão de conhecimentos de natureza técnica, econômica e social, para aumento da produção e produtividade agrícola e a melhoria das condições de vida no meio rural do estado da Paraíba, de acordo com a política de ação dos Governos Federal e Estadual (PARAÍBA, 2014, não paginado).

Além do posto da EMATER as outras únicas entidades que o município possui e que devem prestar apoio às famílias da zona rural é o Sindicato dos Trabalhadores Rurais de Gado Bravo cuja ineficiência já foi discutida e a Secretaria Municipal de Agricultura que também em nada se empenha para apoiar essas famílias.

As poucas famílias que disseram receber assistência técnica ocasionalmente $(10,8 \%)$ ou regularmente $(4,8 \%)$, creditam a prestação desse serviço ao município vizinho, Barra de Santana, que apesar das semelhantes dificuldades que Gado Bravo enfrenta, sua população conta com a presença e atuação efetiva de várias entidades como o Sindicato dos Trabalhadores Rurais de Barra de Santana, a Associação dos Produtores de Leite Conscientes do Vale do Médio Paraíba APLEV/PB, o Serviço Brasileiro de Apoio às Micros e Pequenas Empresas - SEBRAE/PB e o Serviço Nacional de Aprendizagem Rural - SENAR/PB. Desse modo, em função, sobretudo do fato de diversos moradores do município de Gado Bravo serem associados à APLEV-PB consequentemente recebem assistência do SEBRAE - PB que é um parceiro da associação.

Na Figura 7, no que se refere à execução de obras de contenção, 95,1\% das famílias responderam não saber e somente $3,6 \%$ disseram saber executar.

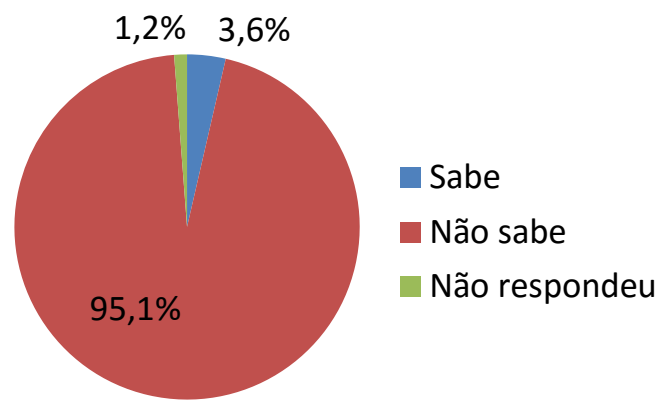

Figura 7: Sabe executar obras de contenção.

Esses dados representam mais um reflexo da falta de apoio às famílias da zona rural de Gado Bravo, principalmente a ausência do poder público, pois sua grande maioria $(95,1 \%)$ desconhece a execução de obras de contenção, não sabem, portanto, evitar problemas anunciados em suas propriedades que só Ihe trarão perdas. Realidade semelhante a da bacia hidrográfica do açude do município de Soledade-PB que que de acordo com Silva (2011), registrou um percentual de $88,9 \%$ de famílias que também não sabem executar obras de contenção

Na segunda e última variável componente da vulnerabilidade tecnológica é abordada a posse de máquinas agrícolas e/ou implementos, conforme a Figura 8, 95,1\% das famílias questionadas disseram possuir alguns, $1,2 \%$ afirmaram não ter nenhum e vale salientar que nenhuma das famílias possui todas as máquinas e/ou implementos (0\%). 


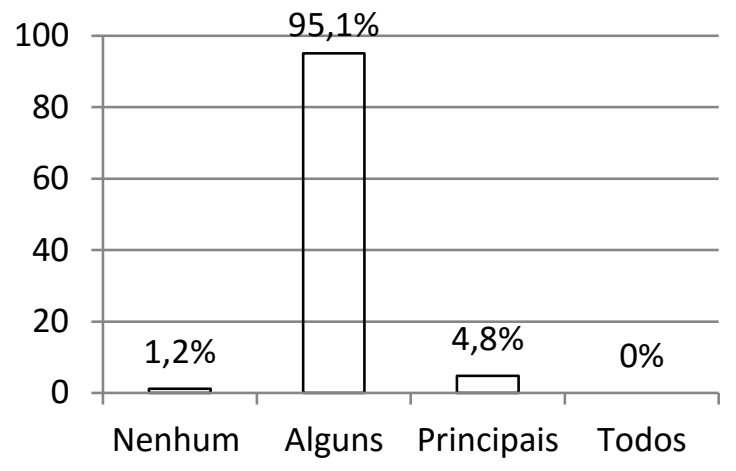

Figura 8: Possui máquinas agrícolas e/ou implementos.

Tal realidade é fruto primeiramente do baixo potencial agrícola que o município possui em virtude da escassez e irregularidade das chuvas e, em segundo, pela ausência de assistência técnica já discutida, fazendo com que expressiva parcela as famílias da zona rural de Gado Bravo $(95,1 \%)$ se limite aos mesmos e poucos tipos de máquinas e implementos utilizados há gerações, comumente rudimentares e de baixa eficiência.

\section{CONCLUSÃO}

Diante do exposto, é possível inferir que o índice de vulnerabilidade tecnológica das famílias da zona rural de Gado Bravo de $68,65 \%$, considerado muito alto ( $>45 \%$ ), é resultante especialmente do predomínio de elementos, como o uso do solo em declive, a falta de conhecimento para a realização de obras de contenção e práticas de conservação, o pequeno uso da irrigação, a quase inexistência de assistência técnica e o pequeno número de máquinas e implementos agrícolas.

Vale salientar que a ínfima ou inexistente assistência técnica é a responsável por todos os outros elementos, o que por sua vez é o não cumprimento da responsabilidade do poder público.

\section{REFERÊNCIAS BIBLIOGRÁFICAS}

1. ACEVEDO DÍAZ, J. A. Cambiando la práctica do cente en la enseñanza de las ciencias a través de CTS, 1996. Disponível em: <http://www.campus-oei.org/salactsi/acevedo2.htm >. Acesso em: 17 dez. 2014.

2. ARAÚJO, A. E. de. Construção social dos riscos e degradação ambiental: município de Sousa, um estudo de caso. Campina Grande, 2002. Dissertação de mestrado-Departamento de Engenharia Agrícola-Universidade Federal de Campina Grande, 2002.

3. BARBOSA, M. P. Vulnerabilidade de risco a desastre. Departamento de Engenharia Agrícola, Universidade Federal da Paraíba. João Pessoa, 1997. 87p.

4. CARDONA, A. O. D. La necessidade de repensar de manera holística los conceptos de vulnerabilidade e riesgo "Uma crítica y uma revisión para la Gestión", Part EN: International Work-Conference on Vulnerability in Desaster Theory and Practice. Anais... Holanda, 2001.

5. CIDADE BRASIL. Município de Gado Bravo. 2012. Disponível em: www.cidadebrasil.com.br/município-gado-bravo-html. Acesso em: 18 dez. 2014. 
6. DUARTE, S. M. A. O desastre da desertificação no município de Taperoá, Estado da Paraíba, Brasil. Campina Grande, 2008. Tese de doutorado-Programa de Pós-graduação em Recursos Naturais-Universidade Federal de Campina Grande, 2008.

7. FARIAS, A. A. de.; et al. Vulnerabilidade tecnológica da população do entorno da bacia hidráulica do açude Manoel Marcionílio, Taperoá/pb. Polêmica, v.12, n.2, p. 322-333, jun. 2013.

8. HOGAN, D. J.; MARANDOLA JÚNIOR, E. Vulnerabilidades e riscos: entre geografia e demografia. Revista brasileira de estatística e população, v.22, n.1, p.29-53, jan./jun. 2005.

9. INSTITUTO BRASILEIRO DE GEOGRAFIA E ESTATÍSTICA-IBGE. Cidades. 2014. Disponível em: <cidades.ibge.gov.br>. Acesso em: 28 mar. 2014.

10. INTERGOVERNMENTAL PANEL IN CLIMATE CHANGE-IPCC. Climate Change 2001: Impacts, Adaptation and Vulnerability, 2001. Disponível em: <www.grida.no/climate/ipcc.../pdf/ wg2TARspm.pdf $\geq$. Acesso em: 08 set. 2014.

11. MORAES NETO, J. M. Gestão de riscos a desastres ENOS (El Ninõ Oscilação Sul) no semi-árido paraibano: uma análise comparativa. Campina Grande, 2003. Tese de doutorado-Programa de Pós-graduação em Recursos Naturais-Universidade Federal de Campina Grande, 2003.

12. PARAíBA. Agência Executiva de Gestão das Águas do Estado da Paraíba-AESA. 2014. Climatologias. Dsponível em: <www.aesa.pb.gov.brz. Acesso em: 04 dez. 2014.

13. PARAÍBA. Empresa de Assistência Técnica e Extensão Rural-EMATER. As origens da Extensão Rural. 2014. Disponível em: <http://www.emater.pb.gov.br/z. Acesso em: 25 nov. 2014.

14. PATRÍ́CIO, M da C. M. O processo de degradação ambiental e seus efeitos socioeconômicos em Cabaceiras-PB. Dissertação de mestrado-Programa de Pós-graduação em Recursos Naturais-Universidade Federal de Campina Grande, 2013.

15. ROCHA, J. S. M. Manual de Projetos Ambientais. Livraria Universitária, Santa Maria-RS, 1997.

16. SOUSA, R. F. Terras agrícolas e o processo de desertificação em municípios do semiárido paraibano. Campina Grande, 2007. Tese de doutorado-Departamento de Engenharia AgrícolaUniversidade Federal de Campina Grande, 2007.

17. SILVA, E. P. Estudo Sócio-Econômico-Ambiental e dos Riscos a Desastres ENOS (El Niño Oscilação Sul) no Município de Picuí - PB: um estudo de caso. Campina Grande, 2002. Dissertação de mestrado-Programa de Pós-graduação em Engenharia Agrícola-Universidade Federal de Campina Grande, 2002.

18. SILVA, M J. da. Dinâmica da degradação ambiental na bacia hidrográfica do açude SoledadePB-Um estudo espaço temporal (1990-2010). Dissertação de mestrado-Programa de Pósgraduação em Recursos Naturais-Universidade Federal de Campina Grande, 2011.

19. VERASZTO, E. V.; et al. Tecnologia: buscando uma definição para o conceito. Prisma.com. v.8, n.7, p. 60-85, dez. 2008.

20. WILCHES-CHAUX, G. La vulnerabilidade global, Part EM: Desastre, Ecologismo y Formación Profissional. Semiárido Nacional de Aprendizaje, Sena. Colômbia, 1989. 